\title{
Correlations Between Alkali and Crystallinity in lyocell-Based ACF Probed with X-Ray Diffraction
}

\author{
Young Min Jin ${ }^{1,2 *}$, Joon Hyuk Lee ${ }^{3}$, and Sang Sun Choi ${ }^{1}$ \\ ${ }^{1}$ Department of Environmental and Energy Engineering, Anyang University, Anyang 14028, Republic of Korea \\ ${ }^{2}$ Korean Standards Coordination Division, Korea Testing Certification, Gunpo 15809, Republic of Korea \\ ${ }^{3}$ Department of Chemical Engineering, Hanyang University, Seoul 04763, Republic of Korea
}

\begin{abstract}
This study examined the effect of alkalis on lyocell-based activated carbon fibres (ACFs) with high Brunauer-Emmett-Teller (BET) surface areas, using X-ray diffraction (XRD). Here, alkali treatments were conducted using $10 \sim 25 \% \mathrm{NaOH}$ and $\mathrm{KOH}$ on lyocell samples for $3 \mathrm{~h}$ at ambient room temperature. A secondary treatment with $4 \%$ each of $\mathrm{KOH}$ and $\mathrm{H}_{3} \mathrm{PO}_{4}$ for an additional $3 \mathrm{~h}$ followed. An activated form of the samples was prepared by oxidation (stabilisation), carbonisation, and activation. The final ACF form of the samples showed a porous structure with high BET surface areas $\left(>1,000 \mathrm{~m}^{2} \mathrm{~g}^{-1}\right)$. A $25 \%$ dosage of $\mathrm{NaOH}$ produced the highest BET surface area compared to other samples. In terms of crystallinity, a $15 \%$ dosage of $\mathrm{KOH}$ was found to be the optimum dosage to secure the highest degree of crystallinity among all samples. Meanwhile, the $\mathrm{NaOH}$ was successfully shifted the samples into the most distinct form of cellulose II. $15 \%$ $\mathrm{NaOH}$ was found to secure the most stable thermal characteristics, as determined via thermo-gravimetric analysis. The present work demonstrates the various physio-chemistries of ACFs prepared with different proportions and types of alkalis, leading to intriguing potential applications.
\end{abstract}

(Received April 28, 2020; Accepted May 26, 2020)

Keywords: crystallisation, x-ray diffraction, thermodynamic properties, fibre, chemical treatment

\section{INTRODUCTION}

Lyocell is a regenerated cellulosic biopolymer fundamental to the development of membranes, films and fibres [1-3]. The fibre form comes from the wood pulp of eucalyptus dissolved in $N$-methyl-morpholine- $N$-oxide, which adheres to the cellulose microfibrils [4]. Lyocell has long attracted attention, particularly for its high degree of nanoscale modification. Alkali alters the physiochemical behaviour of lyocell, viz., the dimensional, mechanical, and supramolecular properties of cellulose II fibres [5-8]. Different pretreatment approaches have been introduced to alter the structure of biomass using $\mathrm{NaOH}$ and $\mathrm{KOH}$ (Figure 1). Some earlier studies employing optical microscopy and X-ray diffraction (XRD) have provided insights in terms of crosslinking between the alkalis and fabric forms of lyocell, and for characterizing the subset

- 진영민·이준혁: 박사과정/연구원, 최상선: 교수 *Corresponding Author: Young Min Jin [Tel: +82-31-428-7538, E-mail: kero0mini@ktc.re.kr] Copyright (c) The Korean Institute of Metals and Materials of physiochemical dynamics. Currently, lyocell approaches are being integrated with precise engineering, with the result that they possess a Brunauer-Emmett-Teller (BET) surface area of more than $1,000 \mathrm{~m}^{2} \mathrm{~g}^{-1}$. However, previous results based on samples with less than $1,000 \mathrm{~m}^{2} \mathrm{~g}^{-1}$ may hinder their adoption in applications. Accordingly, a distinct need exists to determine how alkalis affect the BET surface areas of samples.

One of the drivers of nanocellulose technology is lyocellbased activated carbon fibres. We designate these ACFs for convenience. ACFs are produced in activated fibrous form from fibres and are ideally suited for microelectrodes, nanosheets, and as adsorbents due to their outstanding chemical stability, high flexibility, and small thermal expansion coefficient [9-13]. A theoretical and experimental cornerstone, to determine the supramolecular shift of recently reported ACFs, is critical to understanding how crystallinity varies with different alkali dosages. In a proof-of-principle experiment, we demonstrate the degree of crystallinity of $\mathrm{ACF}$ s via $\mathrm{NaOH}$ and $\mathrm{KOH}$ based fibre modification. We take 

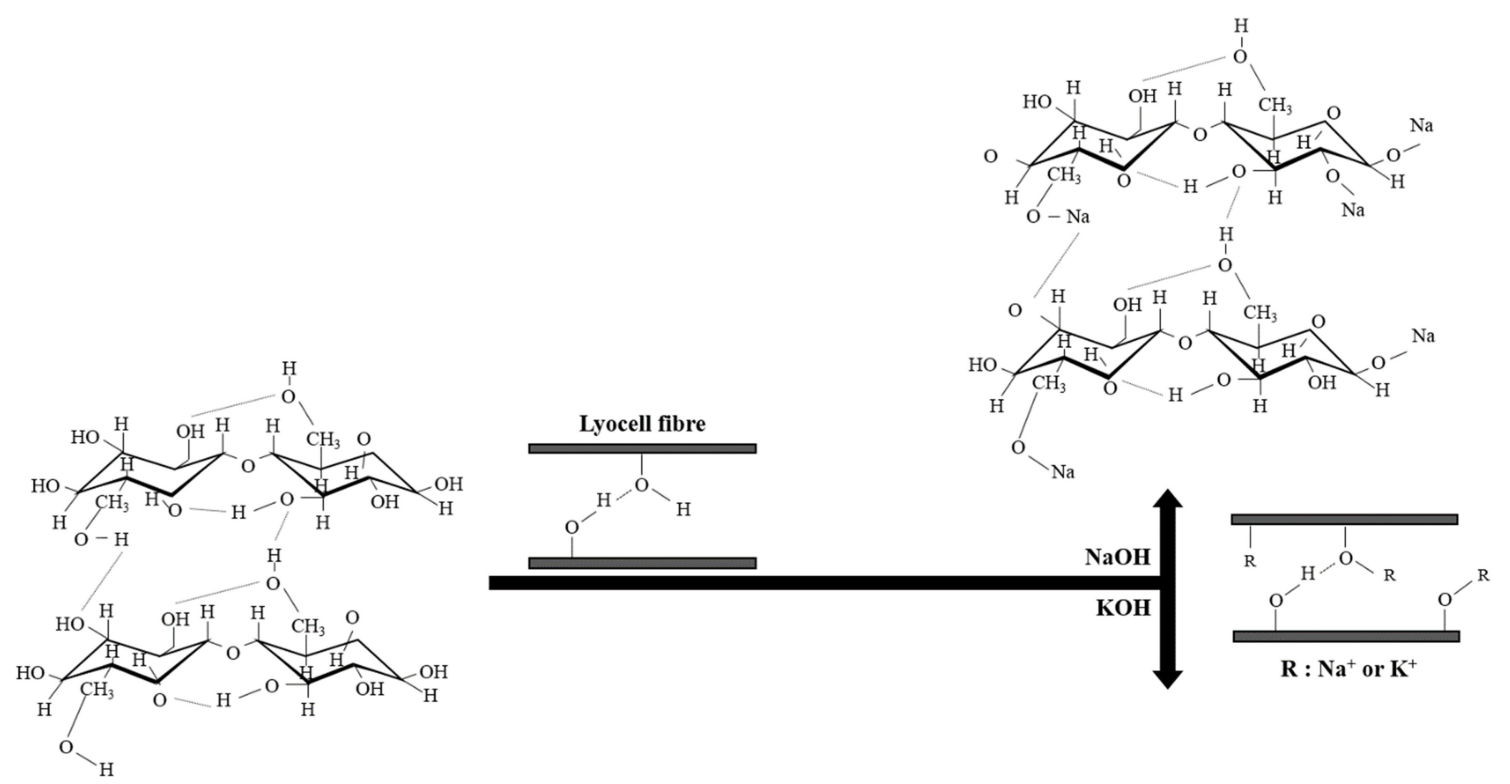

Fig. 1. Proposed mechanism of lyocell fibre by the impregnation of alkalis.

advantage of the X-ray diffraction (XRD) technique to analyze the difference in structural composition produced by various fibre modifications. A thermo-gravimetric analysis (TGA) was also employed to cross-validate and assess the degree of crystallinity. The paper is organized as follows. In Sec. II, we introduce the method of sample preparation and procedures. After describing the experimental setup and techniques used to measure the full probability distributions of the output ACFs, Sec. III is devoted to the analysis of various modifications. Conclusions and further perspectives are given in Sec. IV. The as-prepared ACFs have hierarchically interconnected macro-, meso-, and micropores with a decent surface area. Taking the XRD and TGA results together, we are confident that ACFs de facto obey the general characteristics of lyocell-based fibres, regardless of their BET surface area. Additionally, we also suggest the optimum proportion of impregnating elements under the concept of precise engineering.

\section{EXPERIMENTAL}

\subsection{Synthesis and structural characterization} of samples

A $100 \%$ lyocell fibre was kindly supplied by Hyosung Corporation (South Korea) and used in this work. The denier and filament were $1650 \mathrm{~d}$ and $900 \mathrm{f}$ grade, respectively. The
$\mathrm{NaOH}$ and $\mathrm{KOH}$ alkalis were all analytical reagents and the solutions were all formulated in deionized water. The alkali treatments were performed on fabric pieces of a given dimension $(3 \mathrm{~cm} \times 3 \mathrm{~cm})$ using a batch method. The pieces were padded through the alkali solutions with a nip pressure of 1 bar. The first alkalis treatments employed $10 \sim 25 \%$ of $\mathrm{NaOH}$ and $\mathrm{KOH}$ for $3 \mathrm{~h}$ at ambient room temperature, respectively. The designated proportion of alkalis is shown in Table 1. ACF-W is a counterpart reference sample treated with deionized water. We limited our dosage to $25 \%$ to prevent the possible reduction of crystallinity. The secondary treatment was conducting using $4 \%$ each of $\mathrm{KOH}$ and $\mathrm{H}_{3} \mathrm{PO}_{4}$ for another $3 \mathrm{~h}$ [14]. Note that $\mathrm{KOH}$ was applied to design a porous surface on the sample, while $\mathrm{H}_{3} \mathrm{PO}_{4}$ was applied for better yield in the high temperature range during carbonisation and oxidation [15-16]. Afterwards, the samples were neutralized in deionized water for 10 trials and linedried overnight. An activated form of the samples was prepared using a three step procedure which included oxidation (stabilisation), carbonisation, and activation.

The schematic diagram in Figure 2(a) shows the overall process. $\mathrm{N}_{2}$ gas is released from the $\mathrm{N}_{2}$ gas tank for carbonization, and $\mathrm{H}_{2} \mathrm{O}$ from the heating mantle was included once the activation started. The first step was to oxidize the samples at a constant temperature of $300{ }^{\circ} \mathrm{C}$ with a heating rate of $5^{\circ} \mathrm{C} \min ^{-1}$ for $1 \mathrm{~h}$ (Figure 2(b)). 
Table 1. Samples modified under various proportion of alkali solutions.

\begin{tabular}{|c|c|c|c|}
\hline Classification & First treatment & Secondary treatment & BET surface area $\left(\mathrm{m}^{2} \mathrm{~g}^{-1}\right)$ \\
\hline ACF-N10 & $10 \%$ of $\mathrm{NaOH}$ & \multirow{9}{*}{$\mathrm{KOH}(4 \%)+\mathrm{H}_{3} \mathrm{PO}_{4}(4 \%)$} & 1,072 \\
\hline ACF-N15 & $15 \%$ of $\mathrm{NaOH}$ & & 1,154 \\
\hline ACF-N20 & $20 \%$ of $\mathrm{NaOH}$ & & 1,240 \\
\hline ACF-N25 & $25 \%$ of $\mathrm{NaOH}$ & & 1,298 \\
\hline ACF-K10 & $10 \%$ of $\mathrm{KOH}$ & & 1,011 \\
\hline ACF-K15 & $15 \%$ of $\mathrm{KOH}$ & & 1,046 \\
\hline ACF-K20 & $20 \%$ of $\mathrm{KOH}$ & & 1,109 \\
\hline ACF-K25 & $25 \%$ of $\mathrm{KOH}$ & & 1,121 \\
\hline ACF-W & Deionized water & & 824 \\
\hline
\end{tabular}

(a)
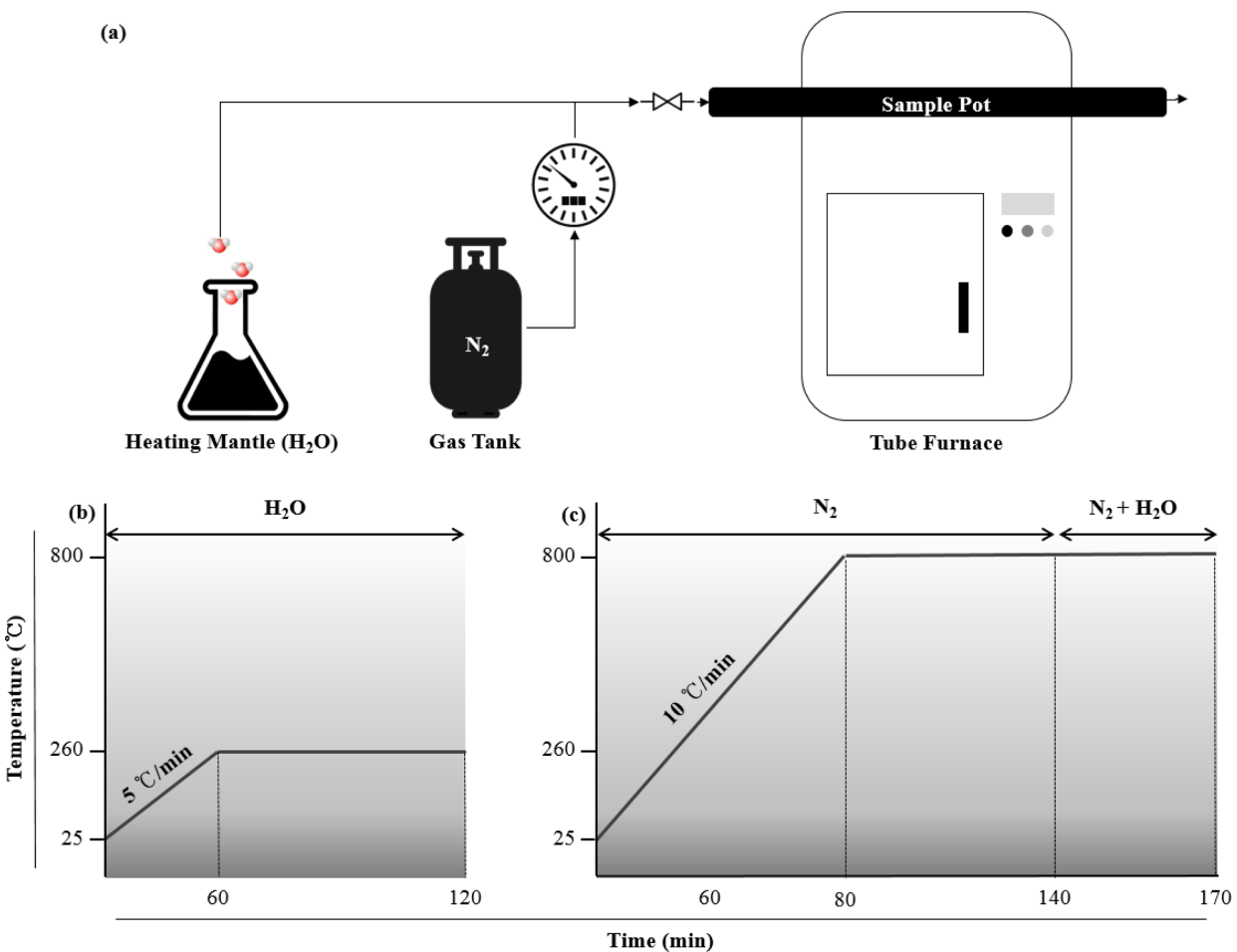

Fig. 2. Schematic diagram for experimental procedures of samples is illustrated in (a). A modulated temperature range of oxidation (stabilisation) is plotted in (b) and (c) shows that of carbonisation and activation.

Subsequently, the samples were heated at a constant rate of $10{ }^{\circ} \mathrm{C} \mathrm{min}-1$ in the presence of a $\mathrm{N}_{2}$ stream $\left(0.5 \mathrm{~L} \mathrm{~min}^{-1}\right)$ up to $800^{\circ} \mathrm{C}$ for $1 \mathrm{~h}$ (Figure 2(c)). Finally, the samples were activated for $30 \mathrm{~min}$ at the same temperature via a mixture of $\mathrm{H}_{2} \mathrm{O}+\mathrm{N}_{2}$ flow. The BET method $\left(\mathrm{N}_{2}-\mathrm{BET}\right)$ revealed that all the modified samples reached more than $1,000 \mathrm{~m}^{2} \mathrm{~g}^{-1}$ (Micrometrics, ASAP2460) [17]. These numerical values suggest that a higher dosage of alkali solutions of either $\mathrm{NaOH}$ or $\mathrm{KOH}$ can result in a higher BET surface area compared to ACF-W. In all circumstances, a treatment of
$\mathrm{NaOH}$ revealed higher BET surface characteristics than $\mathrm{KOH}$. As depicted in Figure 3, the SEM images also supported that the $25 \% \mathrm{NaOH}$ treatment produced the most porous surface structure among all variations.

\subsection{Measurements}

The crystalline structure of the samples was determined using XRD (Bruker, D8 Advance) with monochromatic $\mathrm{CuK} a$ radiation $(\lambda=0.1542 \mathrm{~nm})$ in the Bregg-Brentano reflection geometry $[18,19]$. The analysis was conducted via 

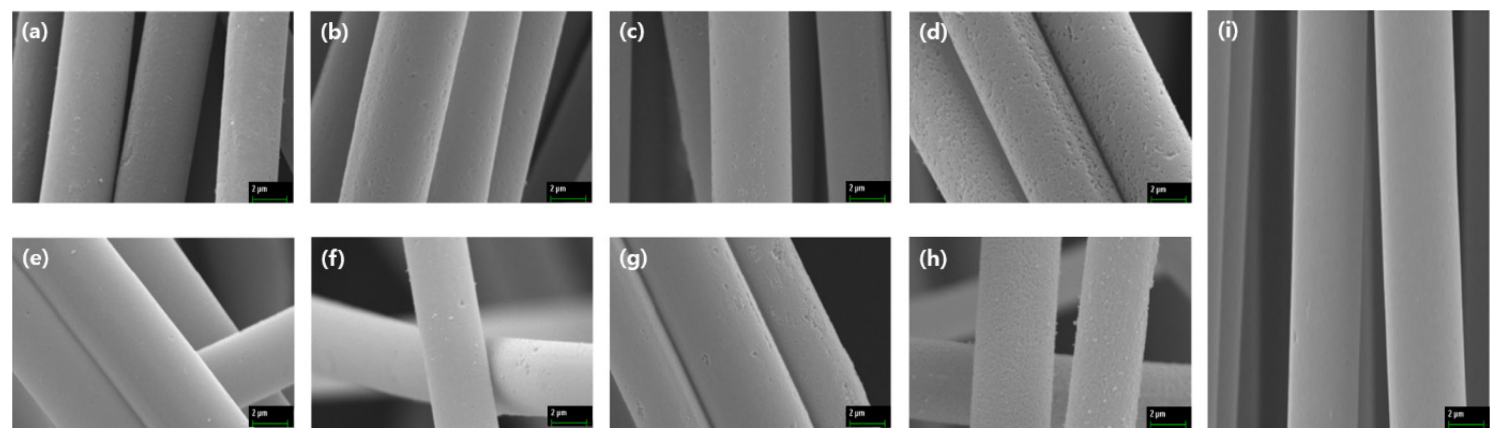

Fig. 3. SEM data for analysis of surface structure before and after the application of alkalis with a magnitude of $x$ 5.0 K. Samples of ACF$\mathrm{N} n$ and $\mathrm{K} n$ are listed in (a)-(d) and (e)-(h), respectively. A counterpart sample of ACF-W is shown in (i). Herein, evenly developed phases of macro-, meso-, and micro-pores were successively observed.

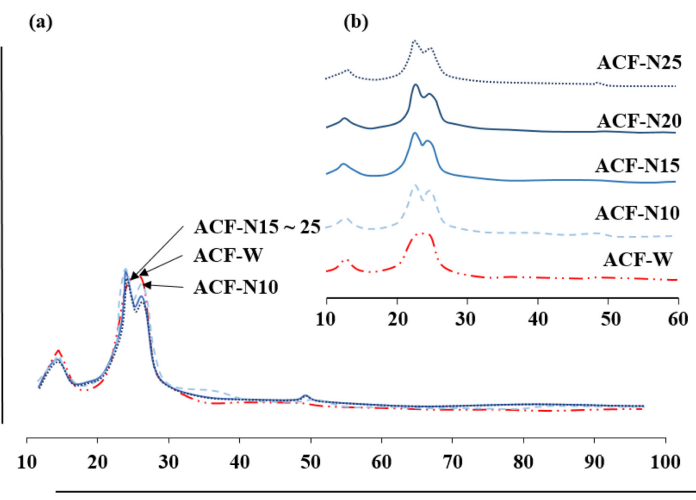

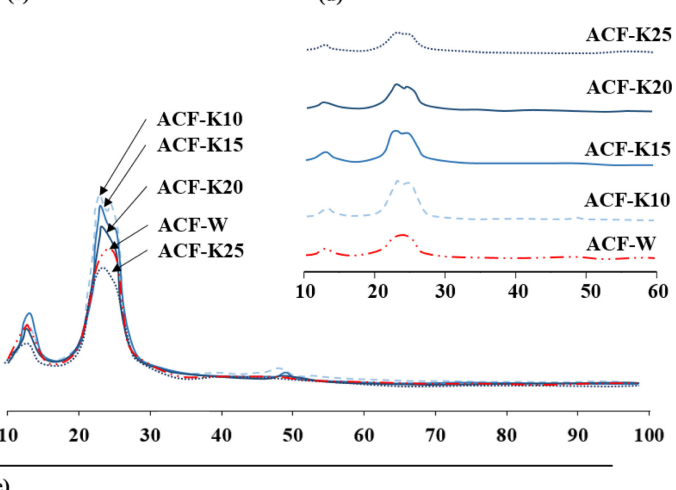

Fig. 4. XRD patterns of (a)-(b) ACF-N $n$ and (c)-(d) ACF-K $n$ versus a counterpart sample of ACF-W.

a designated condition with a step size of $\left(0.02^{\circ}\right), 2 \theta$ range (which varied with the impregnating material), and step time $(0.1 \mathrm{sec})$. The degree of crystallinity (DC) was calculated as the ratio between the corresponding area to the crystalline phase and the total area on the curve, written as Eq. 1;

$$
\% D C=\left(I_{C} / I_{T}\right) \times 100
$$

where $I_{C}$ is the crystalline phase and $I_{T}$ is the total area under the XRD pattern. The thermal stability of the samples was measured through TGA (Sinco, N-1000). The samples were scanned from ambient room temperature to $300{ }^{\circ} \mathrm{C}$ using $\mathrm{N}_{2}$ gas with a heating rate of $5^{\circ} \mathrm{C} \min ^{-1}$ for $100 \mathrm{~min}$.

\section{RESULTS AND DISCUSSION}

Figure 4 provides the XRD spectra of samples, with the peaks labelled to indicate their crystal lattice assignments. The spectra of the modified (ACF-N $n$ and ACF-K $n$ ) samples are clearly different than the pristine sample (ACF-W). The peaks for the shoulder $\left(2 \theta=20^{\circ}\right)$ and the top $\left(2 \theta=22.5^{\circ}\right)$ in the intensity profiles of the alkali-treated samples revealed a tendency to become sharper than that of ACF-W. Interestingly, the intensity increased with an increase in $\mathrm{KOH}$ content of $20 \%$ or less, compared to ACF-W, but the opposite result occurred in ACF-K25. Further, a general trend of anti-correlation between the $\mathrm{KOH}$ dosage and intensity was observed. Here, the ACF-K10 showed the highest DC increment with $2.1 \%$ better crystallinity than ACF-W (Table 2). Meanwhile, the resulting intensity after $\mathrm{NaOH}$ treatment was found to decrease in all cases compared to ACF-W. Such decrements are mainly due to the alkali treatment. The alkali modification swells the lyocell fibres and weakens the dense structure and intermolecular bonds of the fibrous polymer chain [18]. This results in a rearrangement between the cellulose molecules, and drives a transformation from an antiparallel to a parallel conformation. 
Table 2. DC of samples by various impregnation methods.

\begin{tabular}{cc}
\hline Classification & \%DC \\
\hline ACF-N10 & 90.2 \\
\hline ACF-N15 & 90.6 \\
\hline ACF-N20 & 88.8 \\
\hline ACF-N25 & 88.3 \\
\hline ACF-K10 & 93.6 \\
\hline ACF-K15 & 92.1 \\
\hline ACF-K20 & 91.2 \\
\hline ACF-K25 & 87.6 \\
\hline ACF-W & 91.5
\end{tabular}

A characteristic band of $2 \theta=12.3^{\circ}$ was observed in ACF$\mathrm{W}$, which corresponds to the (llll 101 lattice plane. However, there was only a single broadband between $2 \theta=20^{\circ} \sim 22^{\circ}$, indicating that a premature to classify ACF-W as a cellulose II crystallite. In the modified samples, the characteristic peaks of cellulose II were observed Figures 4(b) and 4(d). The observation of major peaks with diffraction angles

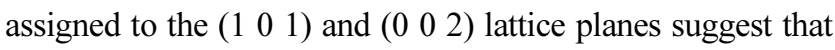
$\mathrm{ACF}-\mathrm{N} n$ and ACF-K $n$ yield fair characteristics of the cellulose II crystallites, which is consistent with previous reports [19]. Overall, $\mathrm{ACF}-\mathrm{N} n$ exhibited more preferable cellulose II crystallites than ACF-Kn, since $\mathrm{Na}^{+}$has a greater hydration radius compared to $\mathrm{K}^{+}$ions [20-22]. It appears that $\mathrm{NaOH}$ treatment may reduce the DC while such change in structure may alter crystallites into a more distinct form of cellulose II. In sum, both $\mathrm{NaOH}$ and $\mathrm{KOH}$ had a visible influence on the DC shift, and thus were vital to controlling alkali concentrations to achieve the target crystallinity for further use.

After treatment in alkalis, the samples were assessed by TGA to further investigate their conformation resulting from thermal gravimetric mass loss. In general, lyocell-based fibres show two phases of weight loss, due to dehydration and decomposition of the cellulose [23]. Figures 5(a) and 5(b) show that the samples obeyed general properties, with a major weight loss at temperatures between $150{ }^{\circ} \mathrm{C}$ and $200{ }^{\circ} \mathrm{C}$ after dehydration. Comparing the alkali treatments performed in this study, both $\mathrm{NaOH}$ and $\mathrm{KOH}$ demonstrated a strong upward linear relationship compared to ACF-W. It is therefore suggested that the thermal stability of the treated samples was improved via the fibre-reinforcing effect [24]. Under similar treatment dosages, ACF-N $n$ holds better thermal stability than ACF-Kn. It was also found that $15 \%$ and $20 \%$ dosages resulted in the best thermal stability in $\mathrm{ACF}-\mathrm{N} n$ and $\mathrm{ACF}-\mathrm{K} n$, respectively.

\section{CONCLUDING REMARKS}

In conclusion, we studied the effect of alkali treatment of ACFs with high BET surface areas. By probing the domain orientations of samples using XRD and TGA, we were able to map the findings as follows.
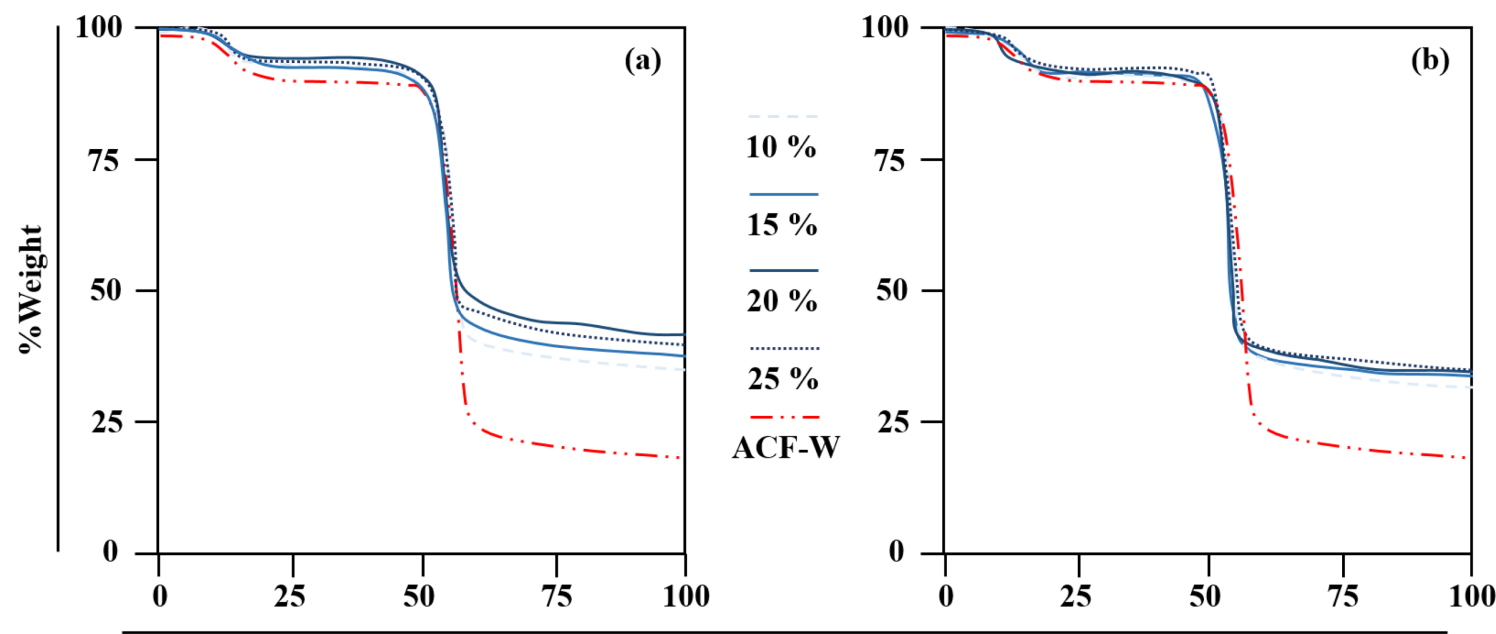

Time (min)

Fig. 5. TGA curves of (a) ACF-N $n$ and (b) ACF-K $n$ versus a counterpart sample of ACF-W. Herein, the bottom axis of Time (min) can be converted to Temperature $\left({ }^{\circ} \mathrm{C}\right)$ by multiplying three. 
(1) A $25 \%$ dosage of $\mathrm{NaOH}$ provided the highest BET surface area with the most porous surface structure compared to other samples.

(2) ACF-K15 showed the highest DC, while the use of 15 $\sim 25 \% \mathrm{NaOH}$ resulted in the most distinct form of cellulose II.

(3) The flame retardancy of samples was improved significantly after alkali treatment. A $15 \%$ of $\mathrm{NaOH}$ was found to provide the best thermal stability among all samples.

(4) Combining all the presented strategies, these findings offer a fundamental route to control the behaviour of ACFs that may aid in the growing field of highly porous material research using lyocell-based fibres.

\section{ACKNOWLEDGEMENTS}

The authors are grateful to the Korea Testing Certification for the use of their facilities.

\section{REFERENCES}

1. K. M. O. Håkansson, A. B. Fall, F. Lundell, S. Yu, C. Krywka, S. V. Roth, G. Santoro, M. Kvick, L. P. Wittberg, L. Wågberg, and L. D. Söderberg, Nat. Commun. 5, 4018 (2014).

2. S. J. Eichhorn, A. Dufresne, M. Aranguren, N. E. Marcovich, J. R. Capadona, S. J. Rowan, C. Weder, W. Thielemans, M. Roman, S. Renneckar, W. Gindl, S. Veigel, J. Keckes, H. Yano, K. Abe, M. Nogi, A. N. Nakagaito, A. Mangalam, J. Simonsen, A. S. Benight, A. Bismarck, L. A. Berglund, and T. Peijs, J. Mater. Sci. 45, 1 (2010).

3. K. Y. Lim, Y. J, Seong, and B. C. Kim, Polym. J. 35, 691 (2003).

4. D. B. Kim, W. S. Lee, S. M. Jo, Y. M. Lee, and B. C. Kim, Polym. J. 33, 139 (2001).

5. R. Sukmawan, H. Takagi, and A. N. Nakagaito. Compos. Part. B-Eng. 84, 9 (2016).

6. A. J. Sayyed, L. V. Mohite, N. A. Deshmukh, and D. V.
Pinjari, Carbohyd. Polym. 206, 220 (2019).

7. H. G. Kim and Y. S. Lee, Carbon. Lett. 29, 529 (2019).

8. S. J. Tan and A. G. Supri, Polym Bull. 73, 539 (2016).

9. J. Wang, J. He, L. Ma, Y. Zhang, L. Shen, S. Xiong, and M. Qu, Chem Eng J. 390, 124508 (2020).

10. P. S. Carraro, L. Spessato, L. H. Crespo, J. T. Yokoyama, J. M. Fonseca, K. C. Bedin, and V. C. Almeida, J. Mol. Liq. 289, 111150 (2019).

11. H. Lu and X. S. Zhao, Sustain. Energ. Fuels 1, 1265 (2017).

12. S. S. Choi, J. H. Lee, Y. M. Jin, and S. H. Lee, Carbon. Lett. 29, 633 (2019).

13. E. Frank, L. M. Steudle, D. Ingildeev, J. M. Spörl, and M. R. Buchmeiser, Angew. Chem. Int. Ed. 53, 5262 (2014).

14. G. Dobele, G. Rossinskaja, G. Telysheva, D. Meier, and O. Faix, J. Anal. Appl. Pyrol. 49, 307 (1999).

15. M. Sevilla, G. A. Ferrero, and A. B. Fuertes. Carbon. 114, 50 (2017).

16. T. Renders, W. Schutyser, S. Van den Bosch, S. F. Koelewijn, T. Vangeel, C. M. Courtin, and B. F. Sels, ACS Catal. 6, 2055 (2016).

17. J. H. Lee, S. H. Lee, and D. H. Suh, Carbon. Lett. 30, 99 (2020).

18. S. Y. Kim and H. S. Lee, Met. Mater. Int, 25, 528 (2019).

19. H. G. Oh, D. K. Park, Y. D. Kim, and M. S. Lee, Korean J. Met. Mater. 57, 808 (2019).

20. R. Aguado, A. F. Lourenço, P. J. Ferreira, A. Moral, and A. Tijero. Cellulose 26, 5925 (2019).

21. B. Satari, K. Karimi, and M. Molaverdi, Bioprocess. Biosyst. Eng. 41, 249 (2018).

22. J. Kielland, J. Am. Chem. Soc. 59, 1675 (1937).

23. M. I. Voronova, S. N. Petrova, T. N. Lebedeva, O. N. Ivanova, A. N. Prusov, and A. G. Zakharov, Fibre. Chem. 36, 408 (2004).

24. A. Jaturapiree, A. P. Manian, M. Lenninger, and T. Bechtold, Carbohyd. Polym. 86, 612 (2011).

25. E. Lizundia, J. L. Vilas, and L. M. León, Carbohyd. Polym. 123, 256 (2015).

26. J. W. Park, T. H. Lee, J. H. Back, S. W. Jang, H. J. Kim, and M. Skrifvars, Compos. Part. B-Eng. 167, 387 (2019). 